\title{
Choosing and Using Tools: Capuchins (Cebus apella) Use a Different Metric Than Tamarins (Saguinus oedipus)
}

\author{
Sarah E. Cummins-Sebree and Dorothy M. Fragaszy \\ University of Georgia
}

\begin{abstract}
Cotton-top tamarins (Saguinus oedipus) selected canes positioned so that a straight inward pull brought food within reach (M. D. Hauser, 1997). Tamarins failed to retrieve food with canes in other positions, and they did not reposition these canes. In this study, tufted capuchin monkeys (Cebus apella) preferred canes they could pull straight in when these were present, but they also repositioned canes in individually variable ways, and their success at obtaining food with repositioned canes improved with practice. In accord with predictions drawn from ecological psychology, capuchins discovered affordances of canes through exploratory actions with these objects, whereas tamarins did not. Ecological theory predicts these differences on the basis of species-typical manipulative activity, and it provides a useful approach for the study of species differences in tool-using behavior.
\end{abstract}

Nonhuman primates are well represented among species that spontaneously use objects as tools, with capuchins (a genus of New World monkeys) topping the list of monkeys as frequent and varied tool users (Anderson, 1996; Fragaszy, Visalberghi, \& Fedigan, 2004; Tomasello \& Call, 1997). One theoretical perspective on tool use in nonhuman primates seeks to explain the observed patterns in terms of causal reasoning (Hauser, 1997; Povinelli, 2000; Visalberghi \& Limongelli, 1994; Visalberghi \& Tomasello, 1998; Visalberghi \& Trinca, 1989). In this perspective, members of a species share a species-normative pattern of reasoning about the physical world. For example, Hauser (1997) presented cottontop tamarins with a choice between two canes to pull in a food treat. The tamarins preferentially chose canes of a certain size and shape, and they chose canes on the basis of the location of the food (i.e., inside the crook of the cane vs. outside the crook). They did not choose canes on the basis of familiarity, color, or texture. Hauser concluded that the tamarins selected canes on the basis of functionally relevant properties for their intended use (to pull in the food). In Hauser's view, the tamarins seemed to have a grasp of at least some of the causal relations involved in using the canes as tools.

Hauser's (1997) interpretation of the tamarins' behavior with canes is couched in terms of the tamarins' possession of concepts

Sarah E. Cummins-Sebree and Dorothy M. Fragaszy, Department of Psychology, University of Georgia.

A summary of this work (without statistics, figures, and specific results) has been included in a book chapter under review ("Capuchins as StoneKnappers?: An Evaluation of the Evidence," in Stone Knapping: The Necessary Conditions for a Uniquely Hominid Behaviour, by V. Roux \& B. Bril [Eds.]). This work was supported in part by National Institutes of Health Grant HD06016 to Georgia State University. We thank Marc Hauser for sharing unpublished data. We also thank Amy Fuller for assistance in collecting and analyzing the data as well as the University of Georgia Instrument Shop for assistance in apparatus construction.

Correspondence concerning this article should be addressed to Sarah E. Cummins-Sebree, who is now at the Department of Behavioral Sciences, Raymond Walters College, University of Cincinnati, 9555 Plainfield Road, Cincinnati, OH 45236. E-mail: cumminsh@ucrwcu.rwc.uc.edu about objects. This argument stipulates that conceptual knowledge about objects guides action and that such knowledge is, in part, innately specified (Spelke, 2000; Wellman \& Gelman, 1998). This view posits an indirect relation between the agent and the environment, mediated by concepts or other forms of mental representations. Here, an animal that chooses what the experimenter has deemed the correct tool on its first presentation demonstrates a conceptual understanding of the functional properties of the tool, whereas an animal that chooses the incorrect tool lacks this understanding. Because tamarins chose canes in accord with their intended use (to pull in another object), Hauser (1997) suggested that the requisite conceptual understanding of object properties for this kind of action was a shared cognitive feature across primates, whether or not they use objects in this way spontaneously. This theory predicts that various primate species will share a bias to choose objects that have appropriate physical characteristics (of position, length, shape, etc.) to serve a given purpose. It does not predict substantive differences across species in choice or action with tools for a given task nor substantive individual differences within species.

An alternative theoretical perspective, ecological psychology (J. J. Gibson, 1979/1986; see Shaw, 2003, for an extended comparison), provides a different interpretive structure for the comparison of tool use across species. In this perspective, animals visually perceive important features of the spatial layout of objects and surfaces directly through information contained in the optic array; this information initially guides action. The animal actively seeks information from the optic array by visual search, and much information is produced by movement occurring in the service of other aims. In the case of manipulative activity, the animal actively seeks additional information not available from the optic array about the properties of objects and about the consequences of various actions with those objects - that is, what the objects afford when acted on in different ways. What it learns from its activity then guides future actions in an ongoing cycle of action and perception (i.e., perceptual learning; E. J. Gibson \& Pick, 2000; J. J. Gibson, 1979/1986). 
The key component to this viewpoint is that an individual's actions guide what information is detected during manipulation, thus constraining what is learned about how the object can be used to afford certain consequences (see Jones, 2003, for a review). Following manipulative activity with objects, knowledge of their affordances guides goal-directed action in new situations (E. J. Gibson, 1988; Lockman, 2000). Initial behavior with an unfamiliar object, often described as random activity or trial-and-error behavior in novice tool users, such as very young children, is interpreted in ecological theory as exploratory actions that can, in principle, generate information about the affordances of objects (Lockman, 2000). Expanding ecological theory to phylogenetic comparisons, differences in tool selection and use in various species are predicted to follow species-typical propensities to explore affordances by manipulating objects, particularly through actions that bring objects into contact with surfaces or other objects (as occurs when an object is used as a tool). Moreover, individuals should show improving skill in tool use with experience in accord with a learning process, and individual differences in action and skill are probable. These predictions are quite different from those generated by the representational view (see Table 1).

Manipulative activity of capuchins and tamarins during foraging generates predictions as to how these species differ in tasks in which an object could be used as a tool. Cotton-top tamarins feed primarily on fruits that they pick with the hands or mouth and insects that they glean by hand from foliage in a manner described by Garber (1993) as nonmanipulative, meaning that they do not rearrange the foliage to find the insects or remove them (see also Singer \& Schwibbe, 1999). Capuchins, conversely, use their hands extensively to extract food items from woody substrates, husks, or shells and to break open hard items by banging them on a hard substrate (Boinski, Quatrone, \& Schwartz, 2000; Fragaszy, 1986; Izawa, 1979; Janson \& Boinski, 1992; Panger, 1998). In captivity, they exhibit varied and generative manipulation of objects (Fra- gaszy \& Adams-Curtis, 1991), routinely combine objects with surfaces, and spontaneously use objects as tools in many ways (reviewed in Fragaszy et al., 2004; Visalberghi \& Fragaszy, in press). Wild capuchins use tools as well, although less commonly than captive capuchins (Fragaszy, Izar, Visalberghi, Ottoni, \& Oliveira, 2004; Fragaszy et al., 2004). These contrasts in spontaneous, routine manipulative activity between cotton-top tamarins and capuchins led us to predict that capuchins, unlike cotton-top tamarins, would discover varied means of using a given object to achieve an end and would act to produce a specific spatial relation between the cane and the food if needed. In sum, we predicted that capuchins would discover and make use of different affordances in the pulling task than did the tamarins tested by Hauser (1997). We also predicted that capuchins would more often than tamarins choose canes that required repositioning to be used effectively. Finally, we predicted that individuals would become more skilled in these actions with practice.

In this study, we replicate Hauser's (1997) procedures with tufted capuchin monkeys, presenting two canes per trial in a paired-comparison design. We scored choice of cane and outcome (success or failure at retrieving the food), and we noted what actions the monkeys produced with the canes. For each experiment, we report group data for comparison with the tamarins in Hauser's (1997) study. We also report the data for individual capuchins to evaluate individual differences in actions with the canes and changes in action over the course of the study.

\section{Experiment 1}

In this experiment, we provided the capuchins with two blue canes. One cane simply required a pull inward for food retrieval (following Hauser, 1997, the correct tool). The other cane (the incorrect tool) required additional manipulation, such as rotating the crook $180^{\circ}$ to the left or right, so that the food was within the

Table 1

Contrasts Between Representational View and Ecological View With Respect to Tool Use in Nonhuman Species

\begin{tabular}{|c|c|c|}
\hline Topic & Representational view & Ecological view \\
\hline Question & $\begin{array}{l}\text { (a) Nature of concepts } \\
\text { (b) Causal reasoning }\end{array}$ & Knowledge for action \\
\hline Source of knowledge & $\begin{array}{l}\text { Mental operations on sensory data; shared species-typical } \\
\text { concepts }\end{array}$ & $\begin{array}{l}\text { Direct perception; individually generated information } \\
\text { through exploratory action }\end{array}$ \\
\hline Comparative predictions & $\begin{array}{l}\text { Individuals will choose objects in accord with a priori } \\
\text { concepts of their functional properties and/or of the } \\
\text { causal relations among objects, surfaces, and actions } \\
\text { (concepts guide action) }\end{array}$ & $\begin{array}{l}\text { (a) Individuals will explore objects and how they can be } \\
\text { used to reach a goal using species-typical } \\
\text { manipulative actions } \\
\text { (b) Individuals will develop idiosyncratic patterns of } \\
\text { using objects for various purposes } \\
\text { (c) Individuals will become more skilled with practice at } \\
\text { using objects to achieve a goal }\end{array}$ \\
\hline Dependent variables & $\begin{array}{l}\text { (a) Choice of object (in accord with prior designation of } \\
\text { correct object for a given purpose) } \\
\text { (b) Form and number of errors in execution or failures in } \\
\text { completion (interpreted as indicating faulty concepts) }\end{array}$ & $\begin{array}{l}\text { (a) Form of action, with attention to variation in action } \\
\text { within and across trials and individuals } \\
\text { (b) Success or failure in completion (interpreted as } \\
\text { indicating appropriate knowledge of affordances of } \\
\text { action with those specific objects to reach a specific } \\
\text { goal) }\end{array}$ \\
\hline
\end{tabular}

Note. Representative writings from the representational point of view include Hauser (1997); Limongelli, Boysen, and Visalberghi (1995); Povinelli (2000); Visalberghi and Tomasello (1998); all writing about nonhuman primates using objects as tools. Representative writings presenting the ecological point of view include [E. J. Gibson and Pick (2000), Lockman (2000), Smitsman (1997), and Smitsman and Bongers (2003), all writing about human children learning to use objects as tools. 
crook and an inward pull would allow for food retrieval. Hauser (1997) required cotton-top tamarins to select the correct tool on 10 of 12 trials across two consecutive test sessions before moving to the next experiment. Because we predicted that capuchins could use either tool to retrieve the food, we used retrieval of the food, rather than choice of a specific tool, on 10 of 12 trials across two consecutive test sessions as the criterion to proceed to the next experiment.

\section{Method}

Subjects. Six male tufted capuchin monkeys (Cebus apella) participated in Experiment 1 (Chris, Leo, Nick, Solo, Xavier, and Xenon), aged 7-12 years. These monkeys were housed at the University of Georgia. They were fed LabDiet (PMI Nutrition International, Richmond, IN) protein chow twice a day and assorted fruit once a day, and water was provided ad libitum. Three monkeys (Xenon, Chris, and Leo) had experience using hoelike tools (Cummins, 1999; Cummins-Sebree \& Fragaszy, 2004), but neither they nor the other 3 monkeys had used cane tools.

Materials. We provided the capuchins with two canes $(0.7 \mathrm{~cm}$ in diameter, $30.5 \mathrm{~cm}$ long, curved to $18.0 \mathrm{~cm}, 3.0 \mathrm{~g}$ in weight) to use for food retrieval. The canes were made from copper tubing, painted blue. We originally attempted to use a molding material, Fimo (Eberhard Faber, Germany), as Hauser (1997) did, but the capuchins quickly destroyed the objects made with this material. The tools were placed on two gray polyvinyl chloride $(\mathrm{PVC})$ platforms $(38.0 \mathrm{~cm}$ long $\times 26.0 \mathrm{~cm}$ wide $\times 10.0$ $\mathrm{cm}$ tall), with a gray PVC divider $(37.0 \mathrm{~cm}$ long $\times 0.6 \mathrm{~cm}$ wide $\times 16.0 \mathrm{~cm}$ above the platforms) between the two platforms; both platforms rested on a rolling metal cart. Small pieces of dried fruit and Cheerios oat cereal were used as treats for retrieval.

The subjects were tested individually in wire mesh cages $(77.0 \mathrm{~cm} \times$ $46.0 \mathrm{~cm} \times 64.0 \mathrm{~cm}$ ) with a clear Plexiglas front panel. A door made of vertical metal rods $(0.5 \mathrm{~cm})$ spaced approximately $4.0 \mathrm{~cm}$ apart in the front panel $(19.0 \mathrm{~cm} \times 18.0 \mathrm{~cm})$ permitted the subjects to reach the tools and platforms. Each trial was videotaped with a Panasonic WV-700 camera and Panasonic VCR (AG-1960) onto videotapes for subsequent data coding.

Procedure. Each subject was placed into the test cage. We baited both platforms with identical pieces of food and placed one cane in the correct orientation (the treat was inside of the crook) and one cane in the incorrect orientation (the treat was outside of the crook) in full view of the monkey. We then placed the platforms in front of the subject but outside of reach for at least $2 \mathrm{~s}$ to ensure the subject had looked at both canes before reaching for one. Then the platforms were pushed closer to the subject so that he could select a cane.

Twelve trials were presented per test session. A trial could end as a success or a failure, regardless of choice. A success occurred when the subject retrieved the treat. A failure could occur in multiple ways: (a) The subject knocked the treat off of the tray or out of the hand's or cane's reach, (b) the subject dropped the cane on the floor before pulling the treat in far enough to be retrieved by hand, or (c) the subject left the work area (with or without the cane) and did not attempt to retrieve the treat for at least $10 \mathrm{~s}$. We recorded the choice made per trial (correct or incorrect) and whether the treat was retrieved (success) or not (failure). To reach criterion, each subject was required to succeed on 10 of 12 trials over two consecutive test sessions.

\section{Results}

Group performance. The 6 capuchins reached criterion in an average of 7.67 sessions (range $=3-12$ sessions). Collectively, the capuchins were more successful when they chose the correct cane ( $n=488$ of 544 trials, $89.7 \%$ ) than when they chose the incorrect cane $(n=15$ of 163 trials, $9.2 \%)$ across the test sessions, $\chi^{2}(3$, $N=707)=395.95, p<.01$.

Individual performance. Though collectively the capuchins chose the correct cane more often than the other cane, 4 subjects met the criterion used by Hauser (1997) (i.e., preference for the correct cane), whereas 2 subjects did not reach the choice criterion, even though they were reliably successful at retrieving treats (see Table 2). Individually, proportions of success with correct canes across sessions ranged from $79.0 \%$ (Xavier, 94 of 119 trials) to $100.0 \%$ (Xenon, 71 of 71 trials). Proportions of success for incorrect canes across sessions ranged from $0.0 \%$ (Nick, 0 of 21 trials) to $32.0 \%$ (Xenon, 8 of 25 trials). Nick was the only subject who did not use the incorrect cane successfully at least once.

Retrieving the treat did not always require the "treat within the crook" method. Four subjects (a) manipulated the cane so that they held the crook and used the end of the handle as a spear, (b) laid the end of the handle on top of the treat to pull it in, or (c) turned the handle toward the treat and swept the treat along the cane inward toward the midline. At least one of these patterns was used once by Chris and Solo, twice by Xenon, and three times by Leo.

Table 2

Number of Choices Made With and Successes at Using Original Blue Canes in Experiment 1

\begin{tabular}{|c|c|c|c|c|c|c|c|c|c|c|c|c|}
\hline \multirow[b]{2}{*}{ Block } & \multicolumn{2}{|c|}{ Chris } & \multicolumn{2}{|c|}{ Leo } & \multicolumn{2}{|c|}{ Nick } & \multicolumn{2}{|c|}{ Solo } & \multicolumn{2}{|c|}{ Xavier } & \multicolumn{2}{|c|}{ Xenon } \\
\hline & Correct & Success & Correct & Success & Correct & Success & Correct & Success & Correct & Success & Correct & Success \\
\hline 1 & 8 & 7 & 7 & 7 & 7 & 6 & 8 & 2 & 7 & 7 & 6 & 7 \\
\hline 2 & 7 & 8 & 9 & 10 & 8 & 7 & 4 & 3 & 9 & 9 & 8 & 10 \\
\hline 3 & 9 & 9 & 10 & 10 & 8 & 7 & 4 & 7 & 11 & 4 & 8 & 9 \\
\hline 4 & 8 & 8 & & & 9 & 8 & 8 & 3 & 9 & 3 & 8 & 9 \\
\hline 5 & 11 & 11 & & & 11 & 10 & 7 & 6 & 10 & 6 & 10 & 10 \\
\hline 6 & 8 & 8 & & & 11 & 11 & 8 & 7 & 10 & 6 & 8 & 10 \\
\hline 7 & 11 & 11 & & & & & 9 & 8 & 8 & 8 & & \\
\hline 8 & 10 & 10 & & & & & 10 & 8 & 11 & 9 & & \\
\hline 9 & & & & & & & 8 & 6 & 11 & 11 & & \\
\hline 10 & & & & & & & 10 & 10 & 10 & 9 & & \\
\hline 11 & & & & & & & 11 & 11 & 12 & 12 & & \\
\hline 12 & & & & & & & & & 11 & 11 & & \\
\hline
\end{tabular}

Note. Numbers in boldface are the higher values when choice and success are compared for each subject. 


\section{Discussion}

The capuchins were able to reach criterion in this task, but (unlike the tamarins in Hauser's [1997] study) their cane selection (correct vs. incorrect) did not always coincide with their success at using the canes. Overall, they succeeded more often when using the correct canes than when using the incorrect canes. However, they occasionally succeeded with the incorrect canes, and 5 of 6 monkeys failed at least once when using the correct cane. Additionally, some subjects used the canes in a different manner than expected on a few trials, bringing in the food without having it in the crook. In Hauser's (1997) study, the purpose of Experiment 1 was to indicate that the tamarins had a concept of insideness, that the inside of the crook was functionally relevant for food retrieval. Restated in the language of ecological psychology, tamarins recognized the affordance of the food inside the crook. The capuchins apparently recognized the same affordance, but the canes also afforded other maneuvers for them, and sometimes they explored these even when they had selected the cane with the food inside the crook.

\section{Experiment 2}

In this experiment, we provided the capuchins with pairs of canes that differed from the original blue canes by one feature: color, shape, size, or texture. For example, we paired a red, regular-sized cane with a blue, thick cane (forcing a choice between familiar color and familiar size). Hauser (1997) found that tamarins chose canes on the basis of size or shape but not on the basis of color or texture. In other words, tamarins preferred red and black canes, as well as textured canes, that were of the same size and shape as the original blue canes; they did not prefer thick, long, or differently shaped canes. Though success at food retrieval was not the primary dependent variable, Hauser noted that most retrieval failures involved the tools of novel shape and size.

Hauser (1997) concluded that the tamarins chose the more appropriate cane on the basis of its relevant features (i.e., the cane that had the same functional properties as the original blue cane). For all these trials, however, the food treats were placed within the crook of each cane, such that there was no correct or incorrect choice. As such, each cane should have been sufficient for successful retrieval. We replicated this experiment with the capuchins to determine whether they would also select canes on the basis of shape and size.

\section{Method}

Subjects. The same 6 male capuchin monkeys participated in this experiment as in Experiment 1. Housing and feeding regimens were unchanged.

Materials. The presentation platform, test cage, and video equipment were identical to those listed in Experiment 1. The canes for this task were constructed from the same copper tubing but differed from the original blue canes in color (red, black), shape (triangle, C-shaped crook), size (thick, long), or texture (containing bumps, containing holes). Those that differed in color, shape, and texture were of the same length $(30.5 \mathrm{~cm})$ and diameter $(0.7 \mathrm{~cm})$ as the original blue canes. The thick cane was $2.1 \mathrm{~cm}$ in diameter but the same length as the original blue canes; the long cane was $8.3 \mathrm{~cm}$ longer in the handle than the original blue canes but of the same diameter. Canes that differed in color and size were presented together, and canes that differed in shape and texture were paired together.
Procedure. We presented the canes in a similar fashion to that given in Experiment 1, except that each treat was placed within a crook of the cane. Each session consisted of 12 trials pairing two properties (color-size or shape-texture), and all subjects received two sessions with each set of paired properties (for a total of four sessions). Of the 12 trials, 4 trials contained two canes that differed on the same feature (e.g., red and black canes, thick and long canes), so that each cane for that pairing appeared on both sides of the platform. The other 8 trials consisted of the different property pairings (e.g., red and thick canes, black and long canes), with each cane appearing equally often in left and right locations.

We scored choice of cane and success at food retrieval for each trial in a similar manner as given in Experiment 1. In accordance with Hauser (1997), we also analyzed the data for choice on the first presentation of each pairing that contained canes that differed on two properties (e.g., red vs. thick cane); this allowed us to determine how the features of the canes in a particular pairing affected initial choice. To calculate proportion of success, we used the first presentation of each pairing of canes that differed on the same property (e.g., red vs. black cane).

\section{Results}

Group performance. The capuchins chose equally between canes that differed in shape and texture (binomial test, $p=1.00$ ); 12 first-pairing selections contained texture changes, and 12 firstpairing selections contained shape changes. The difference in choices made between color and size changes approached significance (binomial test, $p=.06$ ); 17 selections contained the color change, and 7 selections contained the size change.

The monkeys retrieved the food equivalently using canes that varied in texture and shape (Fisher's exact test, $p=.50$ ). The capuchins retrieved the treats on 17 of 18 trials (94.0\%) in which the textured cane was chosen and on 16 of 18 trials $(89.0 \%)$ in which the cane of differing shape was chosen. However, success at food retrieval differed for canes that varied in color and size (Fisher's exact test, $p=.02$ ). The capuchins retrieved the treats on 22 of $23(96.0 \%)$ trials in which the cane of differing color was chosen, but they were successful on only 8 of $13(62.0 \%)$ trials in which the different sized cane was chosen. The capuchins performed poorly with the thick cane (4 of 8 trials ending in success).

Individual performance. Though differences in choices made between color and size approached significance, this trend was due to 3 subjects. Chris and Solo avoided the thick cane ( $n=1$ for each), and Xavier avoided the long cane $(n=3)$. The other 3 subjects did not exhibit an avoidance of those canes across testing ( $n \mathrm{~s}=7,5$, and 5 for the thick cane, and $n \mathrm{~s}=6,6$, and 4 for the long cane for Leo, Nick, and Xenon, respectively).

\section{Discussion}

In Hauser's (1997) study, the tamarins chose canes that differed in color and texture but not in size and shape. Like tamarins, the capuchins in our study selected canes of new colors or textures, but, unlike tamarins, they also selected canes of new sizes or shapes. They succeeded at high and equivalent proportions with the differently shaped and textured canes, except for the thick cane. Half of the capuchins selected the thick cane at least once, and they succeeded with it on half of those trials. Thus, our results indicate that capuchins recognized that they could use all of the objects to retrieve food. 


\section{Experiment 3}

In this experiment, we provided the capuchins with novel canes that differed from the original blue canes in at least one way. The canes differed in color, shape, texture, and position of the tool on the platform. Though these canes could differ from the original blue canes used in Experiment 1 in color, shape, and texture, we focused on the position of the cane in relation to the food for investigation.

Thus, this experiment revisits the notion of insideness, but with novel canes. Hauser (1997) found that tamarins preferentially chose prepositioned canes (canes presented with the crook surrounding the food) compared with convertible canes, even when those prepositioned canes looked very different from the original blue canes. When convertible canes were chosen (in some trials, both canes were convertible canes), the tamarins did not attempt to realign the cane and thus never succeeded at getting the treats (M. D. Hauser, personal communication, June 8, 2001). In our study, we hypothesized that the capuchins would also preferentially select prepositioned canes compared with convertible canes when these were presented together (as less work is needed to use the prepositioned canes effectively) and that they, like the tamarins, would succeed at retrieving the treats with the prepositioned canes. However, we also predicted that, when given only the convertible canes, the capuchins would attempt to reposition those canes to retrieve the treats and that they would occasionally succeed at using them (as they did with the incorrect blue canes in Experiment 1).

\section{Method}

Subjects. The same 6 male capuchin monkeys participated in this experiment as in Experiment 1. Housing and feeding regimens did not change.

Materials. The presentation platform, test cage, and video equipment were identical to those listed in Experiment 1. The canes for this task were constructed from the same copper tubing but differed from the original blue canes on the basis of the following features: color, shape, and texture (see Figure 1). The sizes of these canes were similar to those in Experiments 1 and 2.

Procedure. We presented the canes in a similar fashion to that used in Experiment 1 . There were two sets of 20 trials, and each set was presented twice (for a total of four sessions of testing) to each subject. Of the 20 trials, 10 trials consisted of five pairs of prepositioned canes; each cane for those pairings appeared on both sides of the platform. These trials were intended to allow the subject to retrieve treats and thus maintain interest in the task. Six trials contained three pairs of one prepositioned cane and one convertible cane, with equal left and right locations per cane occurring; these were our probe trials. The remaining 4 trials consisted of two pairings of convertible canes, so that each cane for those pairings occurred on both the left and the right of the platform. These trials were presented to determine the extent to which the monkeys would realign canes and their

\section{Set \#1}

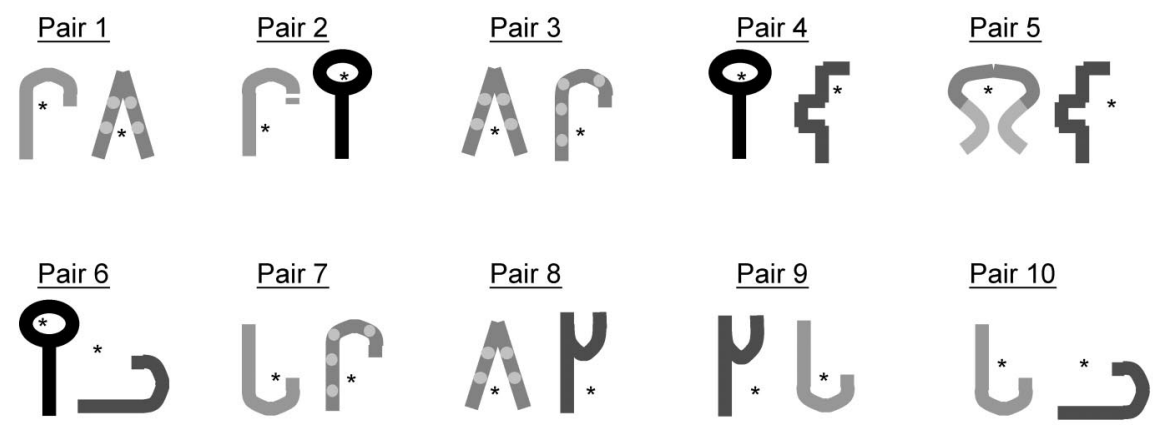

Set \#2

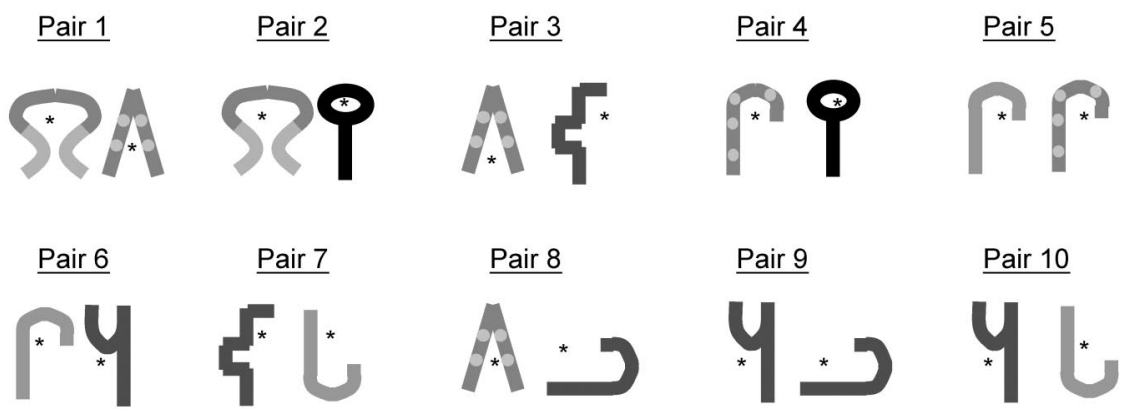

Figure 1. Drawings of the tool pairings for Experiment 3. The different shades of the tools represent different colors. The light-colored dots on two tools (the triangle and one of the regularly shaped hooks) represent bumps. The asterisks represent the food treat. The tools are drawn to illustrate how the tools were presented to the capuchins. 
success at using a realigned cane when a more easily usable cane was not accessible.

We scored choice of cane and success at food retrieval for each trial in a similar manner as in Experiment 1. In accordance with Hauser (1997), we analyzed the choices generated from the first presentation of each pairing that contained prepositioned and convertible canes; this allowed us to determine how the position of the treat relative to the cane in a particular pairing affected choice while reducing the effects of learning. We also computed the proportion of success for both the chosen prepositioned canes that were presented with convertible canes and for all chosen convertible canes across the first presentations of pairings as well as all presentations of cane pairings.

Because convertible canes can theoretically be used if repositioned, we also scored the occurrence of repositioning of the canes on a one-zero basis per trial. We defined repositioning as discernibly altering the position of the cane in any plane, except for the horizontal alteration that occurred when the subject simply pulled the cane directly inward toward the body. Thus, the subject could reposition in many ways: rotating the tool vertically, rotating the tool horizontally, or both. However, a simple pull of the cane in toward the body did not constitute repositioning, as this behavior was the basic requirement for using a prepositioned cane. Repositioning could occur during any point within the trial; thus, repositioning could occur after the capuchin first touched the cane, or it could occur midway through the trial after a direct pull failed to bring the food within reach. We compared the rate of repositioning for both prepositioned and convertible selections. For convertible selections, we noted on how many trials one or more repositioning attempts occurred before each subject first succeeded with a repositioned tool. We also calculated the proportion of success for all trials in which convertible canes were chosen and in which repositioning occurred.

\section{Results}

Group performance. Capuchins chose prepositioned canes significantly more often than convertible canes (binomial test, $p<$ .01) when they were presented together as first-presentation pairings; the capuchins chose the prepositioned canes on 31 of 36 trials $(86.0 \%)$. The subjects also succeeded more often when they chose prepositioned canes than when they chose convertible canes (Fisher's exact test, $p<.01$ ). Of the 31 trials in which prepositioned canes were chosen, the capuchins succeeded at retrieving the food 29 times $(94.0 \%)$. Of the 5 trials in which the convertible canes were chosen over the prepositioned canes, no trials ended in success.

The monkeys repositioned canes on $29.0 \%$ of all the trials in Experiment 3, but they did so differentially on the basis of the position of the cane relative to the treat. The capuchins repositioned convertible canes significantly more often than prepositioned canes, $\chi^{2}(1, N=431)=299.42, p<.05$. They repositioned $13.0 \%$ of the selected prepositioned canes (48 of 318) and $66.0 \%$ of the selected convertible canes (75 of 113).

Individual performance. Only 2 capuchins succeeded (Chris and Xenon) in the first 24 trials (4 trials per monkey; $8.0 \%$ ) in which they encountered both of the novel canes in convertible positions. In the subsequent 72 trials (12 per monkey) in which only convertible canes were presented, 5 monkeys succeeded on 1 to 4 trials each (12 trials total; $17.0 \%$ of 72 ).

Five monkeys required from 4 to 17 trials in which they selected convertible canes before they succeeded with such canes. These monkeys repositioned the convertible canes on 2 to 7 trials before succeeding with a repositioned convertible tool and succeeded, on average, 3.6 (range $=1-7)$ times out of 14.2 (range $=4-20)$ trials in which they selected convertible canes. The proportion of successful trials ranged from $7.0 \%$ (Xavier) to $42.0 \%$ (Chris; $M=$ $25.0 \%$ ). One monkey (Nick) failed on his four repositioning attempts. When repositioning a convertible tool, most monkeys held the canes in the correct manner (i.e., by the long end of the cane and not by the crook). Only Chris held the crook on 2 trials so that he could use the long end to swipe the food to him.

\section{Discussion}

Like the tamarins in Hauser's (1997) study, the capuchins chose the prepositioned canes more often than the convertible canes when these two kinds of canes were paired, and the monkeys succeeded at retrieving the treats more often when using the prepositioned canes. However, capuchins behaved differently than tamarins on trials in which convertible canes were chosen. When they chose convertible canes, the capuchins attempted to reposition them in two thirds of these trials, and they occasionally succeeded at retrieving the food with convertible canes. In contrast, the tamarins never attempted to reposition convertible canes (M. D. Hauser, personal communication, June 8, 2001), and, accordingly, they did not retrieve food in these trials.

\section{Experiment 4}

In Experiment 4, we again presented prepositioned and convertible canes to the capuchins. This time, however, those canes that were prepositioned in Experiment 3 were now positioned so that they were convertible canes in Experiment 4; we called these objects familiar convertible canes to indicate that the monkeys had seen these canes in the previous experiment, but they were positioned so that the treat did not reside within the crook as in Experiment 3. We also presented the capuchins with new prepositioned canes they had not seen before (i.e., novel prepositioned canes).

As in Hauser's (1997) study, the aim of this experiment is to determine which feature of the canes is more relevant to the subjects: the familiarity of the cane, or the position of the treat relative to the cane. Tamarins chose novel prepositioned canes more often than familiar convertible canes (Hauser, 1997). In addition, the tamarins did not attempt to reposition convertible canes when they were chosen (M. D. Hauser, personal communication, June 8, 2001). We predicted that capuchins would also choose canes on the basis of their position relative to the treats and not on the basis of their familiarity and that they would succeed when using the prepositioned canes. We further predicted that the capuchins would attempt to reposition the chosen cane and occasionally succeed at retrieving food, as they did in Experiment 3, when presented with two convertible canes.

\section{Method}

Subjects. The same 6 male capuchin monkeys participated in this experiment as in Experiment 1. Housing and feeding regimens did not change.

Materials. The presentation platform, test cage, and video equipment were identical to those listed in Experiment 1. The canes for this task were constructed from the same copper tubing but differed from the original blue canes in the following features: color, shape, and texture (see Figure 2 for a chart of those canes used in Experiment 4). Some of the canes used in 


\section{Pair 1 \\ Pair 2

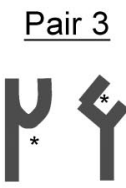 \\ Pair 4 \\ \{.

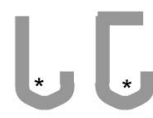 \\ i५

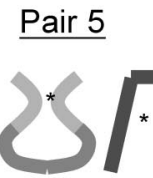

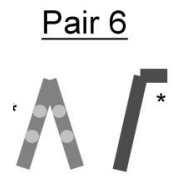
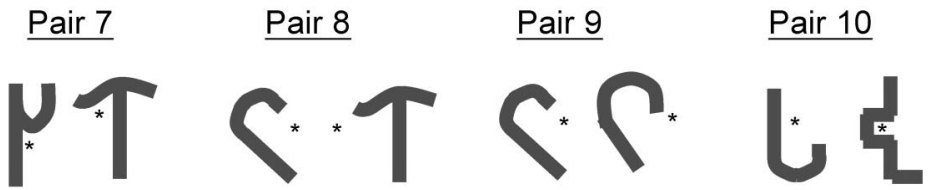

Figure 2. Drawings of the tool pairings for Experiment 4. The different shades of the tools represent different colors. The light-colored dots on one tool (the inverted $\mathrm{V}$ ) represent bumps. The asterisks represent the food treat. The tools are drawn to illustrate their position when presented to the capuchins.

Experiment 3 as prepositioned canes were used in this experiment in new positions as convertible canes. The other canes presented in this experiment were novel. The design of the canes followed that used in Hauser's (1997) study, with one exception: We substituted a different shape for an $\mathrm{H}$-shaped tool because this shape proved too weak to retain its integrity when the capuchins banged it against the tray.

Procedure. We presented the canes in a similar fashion as in Experiment 3 . We presented each capuchin with two sessions, with 20 trials in each session. Of the 20 trials, 8 trials consisted of four pairs of one novel prepositioned and one familiar convertible cane, so that each cane was seen on both sides of the platform. We presented these trials to determine which property was more relevant to the capuchins: familiarity or position. Ten trials contained five pairs of one novel convertible cane and one familiar convertible cane, with equal left and right locations per cane; these were to determine whether familiarity affected cane selection when position remained constant (i.e., both canes in the convertible position). The remaining 2 trials consisted of one familiar convertible and one familiar prepositioned cane; each cane in the pair appeared once on the left and once on the right of the platform. We presented these trials to determine the effect of position of the cane on cane selection with familiarity held constant.

We scored choice of cane and success at food retrieval for each trial in a similar manner as in Experiment 1. In accordance with Hauser (1997), we analyzed the data for choice generated from the first presentation of each pairing that contained novel prepositioned and familiar convertible canes as well as familiar convertible and novel convertible canes; this allowed us to determine how the position of the treat relative to the cane in a particular pairing affected choice while reducing the effects of learning on our analyses. We computed the proportion of trials in which the monkeys succeeded with the chosen prepositioned canes that were presented with convertible canes as well as with all chosen convertible canes, regardless of the position of its paired cane and the familiarity of the chosen canes for the first-presentation pairings and all subsequent pairings. We also scored and analyzed repositioning as we did in Experiment 3.

\section{Results}

Group performance. The capuchins chose the novel prepositioned canes significantly more often than the familiar convertible canes when they were paired together in the first-presentation pairings (binomial test, $p=.01$ ). The subjects chose the novel prepositioned canes on 19 of 24 trials $(79.0 \%)$, which indicates that the position of the cane was the more relevant feature. When familiar and novel canes were presented in only the convertible position, the capuchins chose equally between the two types of canes (binomial test, $p=.86$ ). Of 30 trials, the familiar convertible cane was chosen 14 times $(47.0 \%)$, and the novel convertible cane was chosen 16 times (53.0\%); thus, familiarity did not affect tool selection when position of the cane was kept constant. When convertible and prepositioned canes that were used in Experiment 3 were presented together (i.e., both familiar), the capuchins chose the prepositioned canes significantly more often than the convertible canes (binomial test, $p=.03$ ); all the capuchins always chose the familiar prepositioned cane in all 6 trials in this condition.

The capuchins succeeded more often with the novel prepositioned canes compared with the familiar convertible canes in the first-presentation pairings (Fisher's exact test, $p=.02$ ). They retrieved the treat on 18 of 19 trials $(95.0 \%)$ in which the novel prepositioned cane was chosen but only on 2 of the 5 trials $(40.0 \%)$ in which the familiar convertible cane was chosen. The subjects succeeded equally when choosing between the convertible canes that were familiar or novel, $\chi^{2}(1, N=30)=1.80, p>.10$. They succeeded on 3 of 14 trials $(21.0 \%)$ when using the familiar convertible cane and on 8 of 16 trials $(50.0 \%)$ when using the novel convertible canes. The capuchins retrieved the treat on all 6 trials in which they chose the familiar prepositioned cane when it was paired with the familiar convertible cane. When we combine all trials in which a convertible cane was first chosen, we find that the capuchins succeeded on 13 of 35 trials $(37.0 \%)$. The rate of success was $40.0 \%$ for all convertible cane choices (53 of 131 trials; this includes subsequent presentations).

Retrieving food using convertible canes required repositioning the cane. The monkeys repositioned canes on $57.0 \%$ of all the trials in Experiment 4, but they did so differentially on the basis of the position of the cane relative to the treat (as they did in Experiment 3). The capuchins repositioned convertible canes significantly more often than prepositioned canes, $\chi^{2}(1, N=235)=$ 
$62.19, p<.05$. They repositioned $27.0 \%$ of the selected prepositioned canes (28 of 102) and $80.0 \%$ of the selected convertible canes (106 of 133).

When repositioning convertible canes, all the monkeys succeeded proportionally more often in Experiment 4 than in Experiment 3 (sign test, $n=6, p<.05$ ); their proportion of success with repositioned convertible canes increased from $20.0 \%$ in Experiment 3 to $46.0 \%$ in Experiment 4 . If we combine data across Experiment 3 and Experiment 4, we find that the monkeys succeeded on their 4th to 10th attempts at repositioning convertible canes.

Individual performance. Five monkeys repositioned proportionally more convertible canes in Experiment 4 than in Experiment 3; the average increase in repositioning convertible canes for those 5 monkeys across experiments was $18.0 \%$ (from $64.0 \%$ in Experiment 3 to $82.0 \%$ in Experiment 4). These 5 monkeys succeeded, on average, 8.5 (range $=3-18)$ times out of 17.5 (range $=$ $12-23)$ trials $(M=45.5 \%)$ in which they selected convertible canes. The proportion of successful trials for all 6 monkeys ranged from $25.0 \%$ (Nick and Solo; 3 successes in 12 attempts each) to $78.0 \%$ (Chris and Xenon; 18 successes in 23 attempts each).

Although the monkeys' frequency of success with convertible canes did not rival their success with prepositioned canes in Experiment 4 (whether as a group or individually), their success with convertible canes increased in comparison with their frequency of success with convertible canes in Experiment 3. In Experiment 4, 2 monkeys repositioned the tool and used it successfully on the first trial in which a convertible cane was selected and repositioned, and 2 others succeeded at least once on their first six trials using convertible canes in Experiment 4 (37.0\% of these trials), compared with 2 monkeys succeeding on one trial each in their first six trials with a convertible tool in Experiment 3. All 6 monkeys retrieved the food following repositioning on the fifth try (range $=2-9$ trials).

As in Experiment 3, most monkeys held the convertible canes in the correct manner when repositioning them for food retrieval. However, 2 monkeys repositioned the convertible canes so that the long end could be used to make contact with the food (by holding the crook in the hand). Chris used the long end to swipe the food on two trials, and Xenon did this on one trial. Chris also held the crook and proceeded to stab the treat with the end of the long segment of the tool on two trials.

\section{Discussion}

Like tamarins (Hauser, 1997), the capuchins preferred canes affording simple pulling (i.e., prepositioned canes), without regard to familiarity of the cane, when presented with those options. Capuchins chose such canes on $79.0 \%$ of trials, somewhat less frequently than tamarins in the same situation (cf. Hauser, 1997, Figure 8, p. 302). The capuchins chose equally between familiar and novel canes when both types were presented in the convertible position, which further indicates that familiarity is irrelevant for capuchins when they select a cane, as was also true for tamarins. The capuchins succeeded often with the prepositioned canes, just as they did in Experiment 3.

The two species differed dramatically, however, in their propensity to reposition convertible canes into more appropriate positions. Tamarins never attempted to reposition a cane. The capu- chins routinely attempted to reposition convertible canes, and their rate of success when they did so nearly doubled from Experiment 3 to Experiment 4 (from $25.0 \%$ to $45.0 \%$ ). Capuchins seemed to be learning, in general, how to reposition the canes to increase their chances at retrieving the food, and they were sufficiently interested in this activity to reposition canes even when it was not necessary to do so. Though both tamarins and capuchins seemed to recognize that the position of a cane relative to a piece of food affects its affordances to pull in the food, only the capuchins altered the position of the object to produce an effective spatial relation between cane and food.

\section{General Discussion}

Overall, the capuchins' behavior in the food-retrieval task supports our primary predictions that capuchins and tamarins make use of different affordances of the canes and that the differences correspond with species-typical exploratory actions. Capuchins, like tamarins, perceived the affordance of a cane positioned with the crook surrounding the food (a prepositioned cane): It could be pulled straight in to retrieve a piece of food. Like the tamarins, they preferred to move a cane in this layout, and capuchins and tamarins both usually succeeded at retrieving the food with such canes. However, capuchins routinely and sometimes successfully repositioned canes, even canes that were already positioned so that a straight pull would suffice to retrieve the food. Though they succeeded with canes that they had to reposition proportionally less often than with prepositioned canes, the capuchins increased their rate of success with practice (Experiment 3 to Experiment 4). Tamarins were sensitive to changes in size and shape, but capuchins' choices were not influenced by the color, shape, size, or texture of the canes (Experiment 2). Fujita, Kuroshima, and Asai (2003) reported a similar finding for capuchins given a choice of objects to sweep in a piece of food.

Taken together, the findings from this study with capuchins and Hauser's (1997) study with tamarins provide strong support for the predictions of ecological psychology that embodied perceptual knowledge gained through action supports flexible behavior and that species-typical repertoires of action constrain what an individual learns about the affordances of the world for action (J. J. Gibson, 1979/1986). Both species perceive the initial relation of the cane to the food in the same manner and prefer the cane affording a straight pull. If the spatial relation between cane and food is unsuitable to pull in the food directly, the capuchin acts to alter it, and sometimes the capuchin acts to alter the spatial relation even if the cane was prepositioned for a straight pull. We conclude that, for the capuchin, the problem presented in these experiments includes as one of its manageable elements the spatial relation between the food and the cane. The capuchin can change this relation, just as it routinely acts to change spatial relations between two objects and between objects and surfaces in its daily life. In contrast, for the tamarin, the initial spatial relation between the cane and the food is an unalterable property. If it is unsuitable, the monkey can do nothing about it. In its daily life, the tamarin does not act on the physical environment to alter or produce spatial relations between objects and surfaces.

The representational view, although it predicts that individuals will recognize the relevant affordances of canes and food in different positions, does not predict the form or frequency of 
realignment, nor does it predict improvement in efficiency at realignment. The ecological view does make such predictions, thus providing a richer interpretation of species differences.

One other prediction drawn from ecological psychology was supported. Mastery of repositioning the canes improved with practice. However, even at the end of the study, repositioning the canes presented the monkeys with substantive challenges that they only partially mastered. According to ecological psychology, actors can learn to meet these challenges in accord with their self-generated activity exploring particular instances of the general problem. Just as a beginner golfer must try out different clubs for various situations on the course and learn how to use the clubs by practicing his or her swing, capuchins must practice with various tools and situations to become skilled. In addition, just as golfers develop individual styles of using their clubs, individual capuchins adopted idiosyncratic methods of using the canes.

Ishibashi, Hihara, and Iriki (2000) provided a third example for comparative examination of species differences in flexibility in using objects to pull in food. Ishibashi et al. (2000) showed that Japanese macaques would pull a hoe-shaped object $(20.0 \mathrm{~cm}$ long) inward across a smooth surface to retrieve a piece of food but that the monkeys needed extensive practice to do so with different orientations of the tool (i.e., food lying outside of the area of the blade such that a lateral movement was needed).

Ishibashi et al. (2000) included a few trials in each session in which the hoe was oriented with the head close to the monkey and the handle facing away. The monkeys did not turn the hoe around in these trials; instead, they grasped the head and tried to contact the food with the narrow handle. The experimenters also gave the monkeys novel ring-shaped or hoe-shaped objects. The monkeys did not try to contact the food with the ring-shaped objects. However, they did try with novel hoe-shaped objects and succeeded at retrieving the food with them, although they moved the novel objects more awkwardly than the familiar hoe.

Ishibashi et al.'s (2000) monkeys behaved similarly to the capuchins (this study) and tamarins (Hauser, 1997) in Experiment 1 , in which food was positioned inside one cane and outside another. The macaques also illustrate, as did the capuchins, the process of exploration and discovery of the affordances of actions with objects and the gradual mastery of producing useful spatial relations between an object and a piece of food. They seem intermediate between tamarins and capuchins in their aptitude for producing effective spatial relations between a long object held in the hand and a small piece of food at a distance. Generation of lateral movements with a hoelike object was more difficult for the macaques than for the capuchins, judging from the descriptions of the macaques' initial attempts with the hoe. The macaques required hundreds of trials to become skilled at sweeping the hoe laterally and inward across a smooth surface. The capuchins, in contrast, received 204 to 312 trials (depending on the number of sessions required to reach criterion in Experiment 1), and they mastered far more difficult movement problems than did the macaques (e.g., rotation of an object combined with lateral movement).

The character of species-typical actions, according to ecological theory, constrains the discovery of affordances. Despite their considerable dexterity in prehending small objects (Christel, 1993), macaques are not generally disposed to reposition objects. Their foraging activities primarily involve grasping small food items and placing them directly in the mouth. Occasionally, however, macaques manipulate inedible objects (e.g., rubbing small objects together, as in stone handling; Huffman, 1984). Macaques, perhaps, could master repositioning a tool by rotation to create an effective spatial relation between the object and food in a retrieval task, but we predict that rotation of the object would not be as easily discovered by their typical exploratory movements with the tool as would a lateral movement.

There remains an important empirical issue to address in comparing behavior with canes: the biomechanical demands of moving the canes for animals of different body sizes. Hauser (1997) provided canes of $15.0-25.0 \mathrm{~cm}$ in his experiments (M. D. Hauser, personal communication, September 26, 2004). To judge whether the canes given to tamarins and capuchins were proportionally about the same length, we compared arm lengths and body weights. The average length of the radius plus humerus for tamarins is $10.4 \mathrm{~cm}$ (Hershkovitz, 1977); these monkeys weigh, on average, $411 \mathrm{~g}$ (Fleagle, 1999). The average length for capuchins of the upper arm plus forearm is $24.9 \mathrm{~cm}$ (Fragaszy, Adams-Curtis, Baer, \& Carlson-Lammers, 1989), and males average $3.65 \mathrm{~kg}$ (Fleagle, 1999); thus, male tufted capuchins are about eight times as heavy as cotton-top tamarins, and their arms are 2.0-2.5 times as long. The $18.0-\mathrm{cm}$ canes presented to the capuchins were therefore proportionally much shorter and probably proportionally much lighter than the $15.0-25.0 \mathrm{~cm}$ canes given to the tamarins by Hauser (1997). The 4 male Japanese macaques tested by Ishibashi et al. (2000) weighed 3-5 kg, overlapping with the weights of the male tufted capuchins in our study $(3-4 \mathrm{~kg})$. The $20.0-\mathrm{cm}$ T-shaped acrylic object the macaques wielded was probably proportionally about as long and heavy for them as the canes wielded by the capuchins. It is an empirical question whether tamarins given objects of a proportionally similar length and weight as the objects given to the capuchins and Japanese macaques would behave differently with the canes than did Hauser's tamarins. We hope that the study will be replicated to answer this question. We also suggest that investigators report more details about the weight and dimensions of objects used in experiments concerning tool use.

As a larger contribution, this study illustrates the value of the ecological approach to the study of flexible instrumental behavior (problem solving and tool use) in nonhuman species. Ecological psychology makes the general prediction that spontaneous, species-typical combinatorial manipulation in everyday life predicts the forms and flexibility of tool use in experimental or unusual circumstances (i.e., it predicts species and individual differences in problem-solving behavior). It can support principled interpretation of initial activity and of changes in performance with practice. It provides a biologically grounded approach for the comparative study of flexible and adaptive behavior, and it encourages linkages with other domains of biological sciences (e.g., developmental psychology, movement sciences, cognitive sciences). We look forward to wider use of this perspective in comparative studies with nonhuman species.

\section{References}

Anderson, J. R. (1996). Chimpanzees and capuchin monkeys: Comparative cognition. In A. E. Russon, K. A. Bard, \& S. T. Parker (Eds.), Reaching into thought: The minds of the great apes (pp. 23-56). New York: Cambridge University Press. 
Boinski, S., Quatrone, R., \& Schwartz, H. (2000). Substrate and tool use by brown capuchins in Suriname: Ecological contexts and cognitive bases. American Anthropologist, 102, 741-761.

Christel, M. (1993). Grasping techniques and hand preferences in Hominoidea. In H. Preuschoft \& D. J. Chivers (Eds.), Hands of primates (pp. 91-108). New York: Springer-Verlag.

Cummins, S. E. (1999). Detection of environmental constraints in a tooluse task by tufted capuchin monkeys (Cebus apella). Unpublished master's thesis, University of Georgia.

Cummins-Sebree, S. E., \& Fragaszy, D. M. (2004). Detecting environmental constraints during tool-use by capuchin monkeys (Cebus apella). Manuscript in preparation.

Fleagle, J. G. (1999). Primate adaptation and evolution (2nd ed.). New York: Academic Press.

Fragaszy, D. M. (1986). Time budgets and foraging behavior of wedgecapped capuchins (Cebus olivaceus): Age and sex differences. In D. Taub \& F. King (Eds.), Current perspectives in primate social dynamics (pp. 159-174). New York: Van Nostrand.

Fragaszy, D. M., \& Adams-Curtis, L. E. (1991). Generative aspects of manipulation in tufted capuchin monkeys (Cebus apella). Journal of Comparative Psychology, 105, 387-397.

Fragaszy, D., Adams-Curtis, L., Baer, J., \& Carlson-Lammers, R. (1989). Forelimb dimensions and goniometry of the wrist and fingers in tufted capuchin monkeys (Cebus apella): Developmental and comparative aspects. American Journal of Primatology, 17, 133-146.

Fragaszy, D. M., Izar, P., Visalberghi, E., Ottoni, E. B., \& Oliveira, M. (2004). Wild capuchins use anvils and stone tools. American Journal of Primatology, 64, 359-366.

Fragaszy, D. M., Visalberghi, E., \& Fedigan, L. (2004). The complete capuchin: The biology of the genus Cebus. Cambridge, England: Cambridge University Press.

Fujita, K., Kuroshima, H., \& Asai, S. (2003). How do tufted capuchin monkeys understand causality involved in tool use? Journal of Experimental Psychology, 29, 233-242.

Garber, P. (1993). Feeding ecology and behaviour of the genus Saguinus. In A. B. Rylands (Ed.), Marmosets and tamarins: Systematics, behaviour, and ecology (pp. 273-295). Oxford, England: Oxford University Press.

Gibson, E. J. (1988). Exploratory behavior in the development of perceiving, acting, and the acquiring of knowledge. Annual Review of Psychology, 39, 1-41.

Gibson, E. J., \& Pick, A. D. (2000). An ecological approach to perceptual learning and development. New York: Oxford University Press.

Gibson, J. J. (1986). The ecological approach to visual perception. Boston: Houghton Mifflin. (Original work published 1979)

Hauser, M. D. (1997). Artifactual kinds and functional design features: What a primate understands without language. Cognition, 64, 285-308.

Hershkovitz, P. (1977). Living New World monkeys: Vol. 1. Platyrrhini. Chicago: University of Chicago Press.

Huffman, M. (1984). Stone-play of Macaca fuscata in Arashiyama B troop: Transmission of a non-adaptive behavior. Journal of Human Evolution, 13, 725-735.

Ishibashi, H., Hihara, H., \& Iriki, A. (2000). Acquisition and development of monkey tool-use: Behavioral and kinematic analyses. Canadian Journal of Physiology and Pharmacology, 78, 958-966.

Izawa, K. (1979). Foods and feeding behavior of wild black-capped capuchins. Primates, 20, 57-76.
Janson, C. H., \& Boinski, S. (1992). Morphological and behavioral adaptations for foraging in generalist primates: The case of the Cebines. American Journal of Physical Anthropology, 88, 483-498.

Jones, K. S. (2003). How shall affordances be refined? Four perspectives. Ecological Psychology, 2, 107-195.

Limongelli, L., Boysen, S., \& Visalberghi, E. (1995). Comprehension of cause and effect relationships in a tool-using task by common chimpanzees (Pan troglodytes). Journal of Comparative Psychology, 109, 18 26

Lockman, J. J. (2000). A perception-action perspective on tool use development. Child Development, 71, 137-144.

Panger, M. (1998). Object-use in free-ranging white-faced capuchin monkeys (Cebus capucinus) in Costa Rica. American Journal of Physical Anthropology, 106, 311-321.

Povinelli, D. (2000). Folk physics for apes: The chimpanzee's theory of how the world works. Oxford, England: Oxford University Press.

Shaw, R. (2003). The agent-environment interface: Simon's indirect or Gibson's direct coupling? Ecological Psychology, 15, 37-106.

Singer, S. S., \& Schwibbe, M. H. (1999). Right or left, hand or mouth: Genera-specific preferences in marmosets and tamarins. Behaviour, 136, 119-145.

Smitsman, A. W. (1997). The development of tool use: Changing boundaries between organism and environment. In C. Dent-Read \& P. ZukowGoldring (Eds.), Evolving explanations of development: Ecological approaches to organisms-environment systems (pp. 301-329). Washington, DC: American Psychological Association.

Smitsman, A. W., \& Bongers, R. M. (2003). Tool use and tool making: A dynamical developmental perspective. In J. Valsiner \& K. Connolly (Eds.), Handbook of developmental psychology (pp. 172-193). London: Sage.

Spelke, E. (2000). Core knowledge. American Psychologist, 55, 1233 1243.

Tomasello, M., \& Call, J. (1997). Primate cognition. New York: Oxford University Press.

Visalberghi, E., \& Fragaszy, D. (in press). Tool use: A challenge for capuchins, a challenge for us. In E. A. Wasserman \& T. R. Zentall (Eds.), Comparative cognition: Experimental explorations of animal intelligence. Oxford, England: Oxford University Press.

Visalberghi, E., \& Limongelli, L. (1994). Lack of comprehension of cause-effect relations in tool-using capuchin monkeys (Cebus apella). Journal of Comparative Psychology, 108, 15-22.

Visalberghi, E., \& Tomasello, M. (1998). Primate causal understanding in the physical and psychological domains. Behavioural Processes, 42, 189-203.

Visalberghi, E., \& Trinca, L. (1989). Tool use in capuchin monkeys: Distinguishing between performing and understanding. Primates, 30, 511-521.

Wellman, H., \& Gelman, R. (1998). Knowledge acquisition in foundational domains. In W. Damon (Series Ed.), D. Siegler, \& R. Siegler (Vol. Eds.), Handbook of child psychology: Vol. 2. Cognition, perception \& language (5th ed., pp. 523-573). New York: Wiley.

Received April 7, 2004

Revision received November 10, 2004

Accepted November 14, 2004 